\title{
Correction: SOX18 promotes gastric cancer metastasis through transactivating MCAM and CCL7
}

Jie Chen · Yunzhi Dang $\cdot$ Weibo Feng $\cdot$ Chenyang Qiao - Danfei Liu - Tongyue Zhang $\cdot$ Yijun Wang - Dean Tian • Daiming Fan $\cdot$ Yongzhan Nie $\cdot$ Kaichun $\mathrm{Wu} \cdot \operatorname{Limin} \mathrm{Xia}$

Published online: 21 May 2021

(c) The Author(s), under exclusive licence to Springer Nature Limited 2021

Correction to: Oncogene

https://doi.org/10.1038/s41388-020-1378-1

In the original version of this article, the authors noted that they accidentally misplaced the data belonging to Fig. $5 \mathrm{~F}$ when assembling the figure. The amended version of Fig. $5 \mathrm{~F}$ is provided below. This change does not affect the results or conclusions reported in the manuscript. The authors sincerely apologize for any inconvenience we caused. 
Figure 5F. Representative BLI images of the indicated groups are shown at the indicated time points.
The original article has been corrected.
A

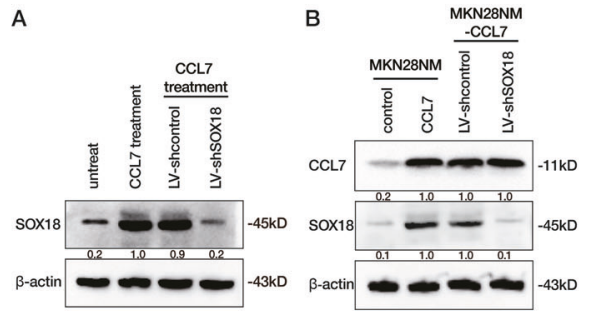

C
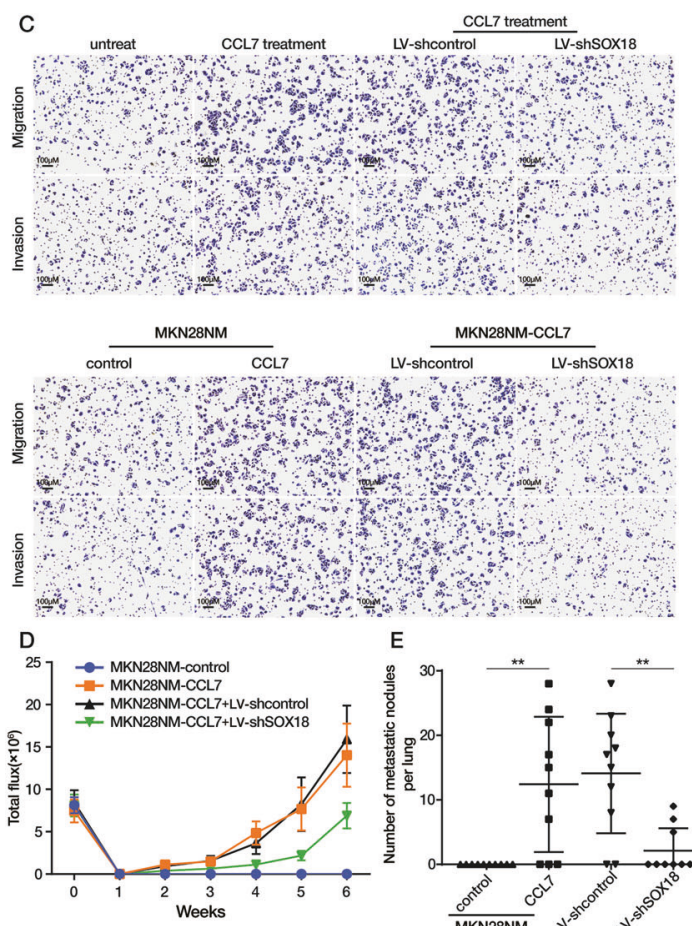

E
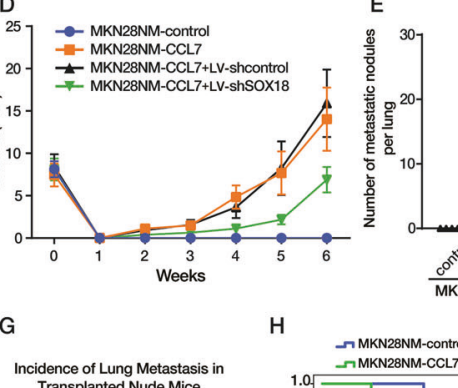

Incidence of Lung Metastasis in
Transplanted Nude Mice

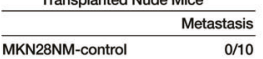

$\begin{array}{ll}\text { MKN28NM-control } & 0 / 10 \\ \text { MKN28NM-CGL7 } & 7 / 10\end{array}$

MKN28NM-CCL7+LV-shcontrol $8 / 10$

MKN28NM-CCL7+LV-shSOX18 $3 / 10$

$\mathrm{H}$

$H$ M MKN28NM-Control
$\rightarrow$ MKN28NM-CCL7
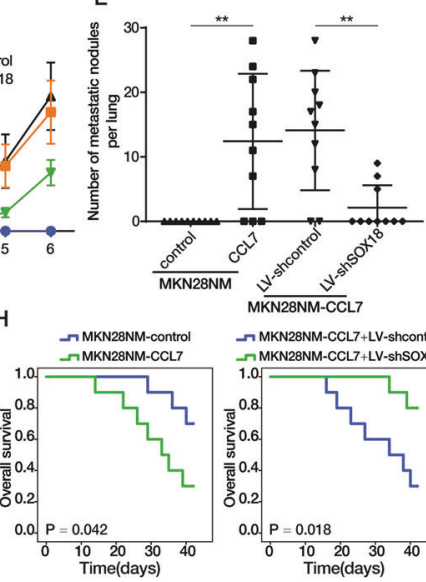

MKN28NM-CCL7

$\rightarrow$ MKN28NM-CCL7+LV-shoontrol
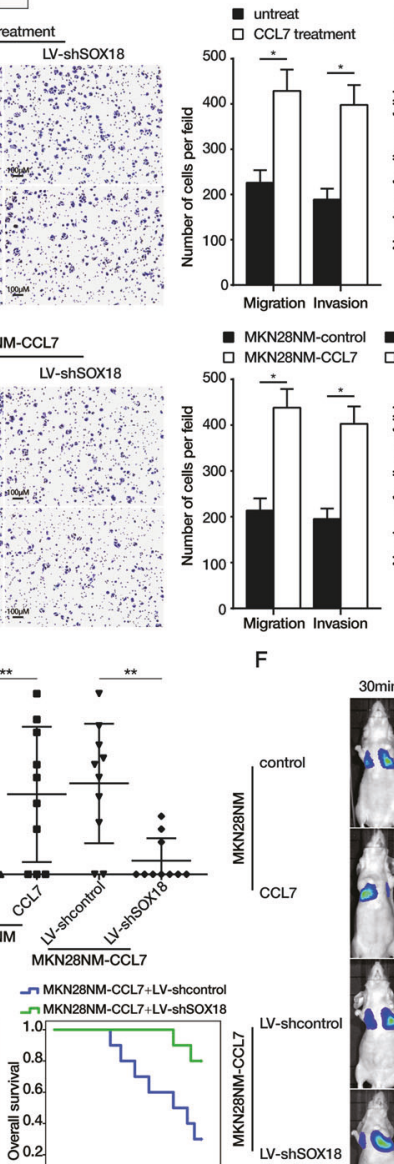

- LV-shcontrol $]$ cCL7 treatment

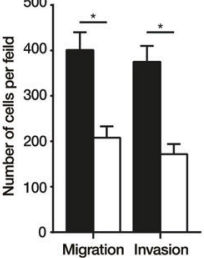

- MKN28NM-control - MKN28NM-CCL7 + LV-shcontro

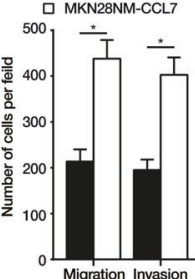

$\mathrm{F}$
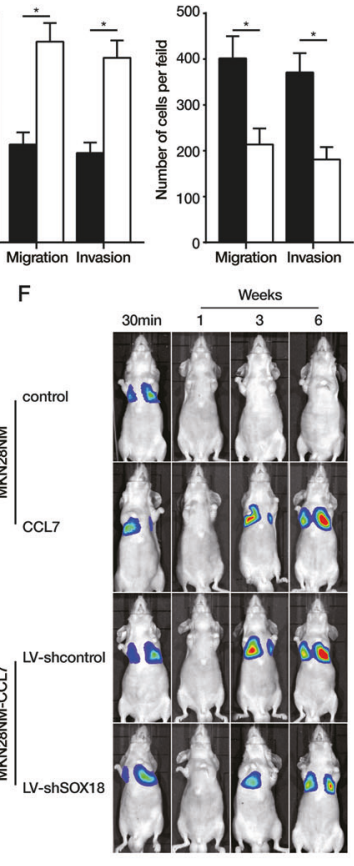

MKN28NM-CCL7

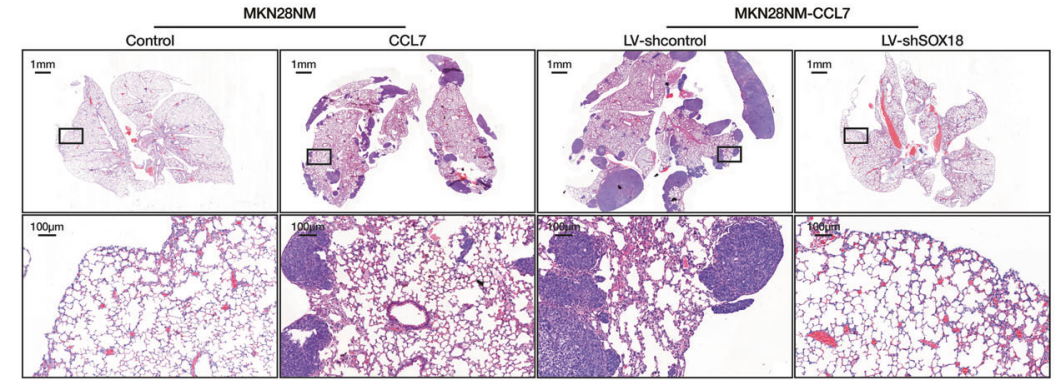

